\title{
Needle knife recanalization of a complete post-transplant bile duct stricture
}

Benign biliary strictures are established complications after liver transplantation, commonly occurring at the duct-to-duct anastomosis [1]. Severe anastomotic strictures may not be amendable to the gold standard endoscopic therapy.

A 65-year-old-man with a history of alcoholic cirrhosis who had undergone liver transplantation 1 year previously was referred for endoscopic retrograde cholan-

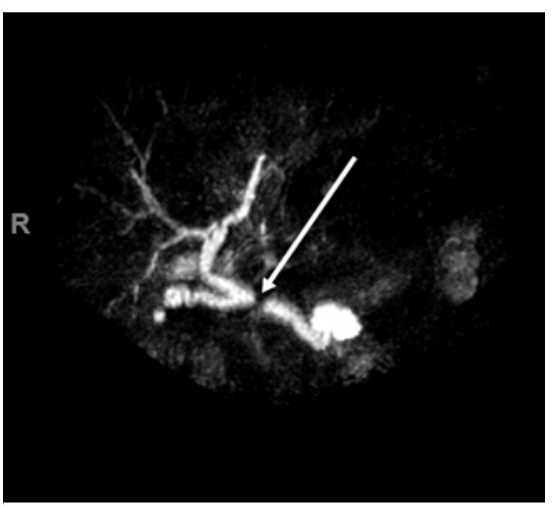

- Fig. 1 Magnetic resonance cholangiopancreatography (MRCP) image showing a severe, short localized stricture. giography (ERCP) after outpatient laboratory evaluation revealed signs of cholestasis and magnetic resonance cholangiopancreatography (MRCP) revealed a complete anastomotic stricture (\$Fig.1). ERCP was performed and confirmed these findings; in addition, difficulty was encountered while attempting to traverse the stricture with a 0.025 -inch guidewire ( Fig.2a). Cholangioscopy was performed, but manipulation with cholangioscopic biopsy forceps was unsuccessful. The guidewire was downsized to a 0.018 -inch wire and the stricture was traversed; however, attempts to dilate the anatomic stricture with various dilating catheters were unsuccessful. A needle knife was then loaded over the guidewire, electrocautery was applied, and the stricture was recanalized successfully ( $\triangleright$ Video 1). After this maneuver, there was no evidence of contrast extravasation, which would have suggested bile duct injury ( $\mathbf{F i g} \mathbf{2} \mathbf{2}$ ). A follow-up ERCP 4 weeks later revealed improvement in the anastomotic stricture and a 0.035inch guidewire was easily passed beyond the stricture ( $\boldsymbol{F i g} . \mathbf{2 s c}$ ). This allowed for routine biliary balloon dilation to $6 \mathrm{~mm}$ and placement of a 12-cm 11.5-Fr stent. Bile duct recanalization has previously been achieved using a combined percutaneous and endoscopic approach [2]. Gupta et al. used a specific needle knife for puncture that allowed a wire to pass through the needle and stricture [3]. Recently, a standard needle knife has been used to cut and puncture these strictures [4]. In our case, cholangioscopic guidance was first used to pass a wire, which allowed for a controlled cut using the loaded needle knife. This technique may be used as a minimally invasive alternative to surgical repair in short anastomotic strictures.

Endoscopy_UCTN_Code_TTT_1AR_2AG

\section{Competing interests}

The authors declare that they have no conflict of interest.
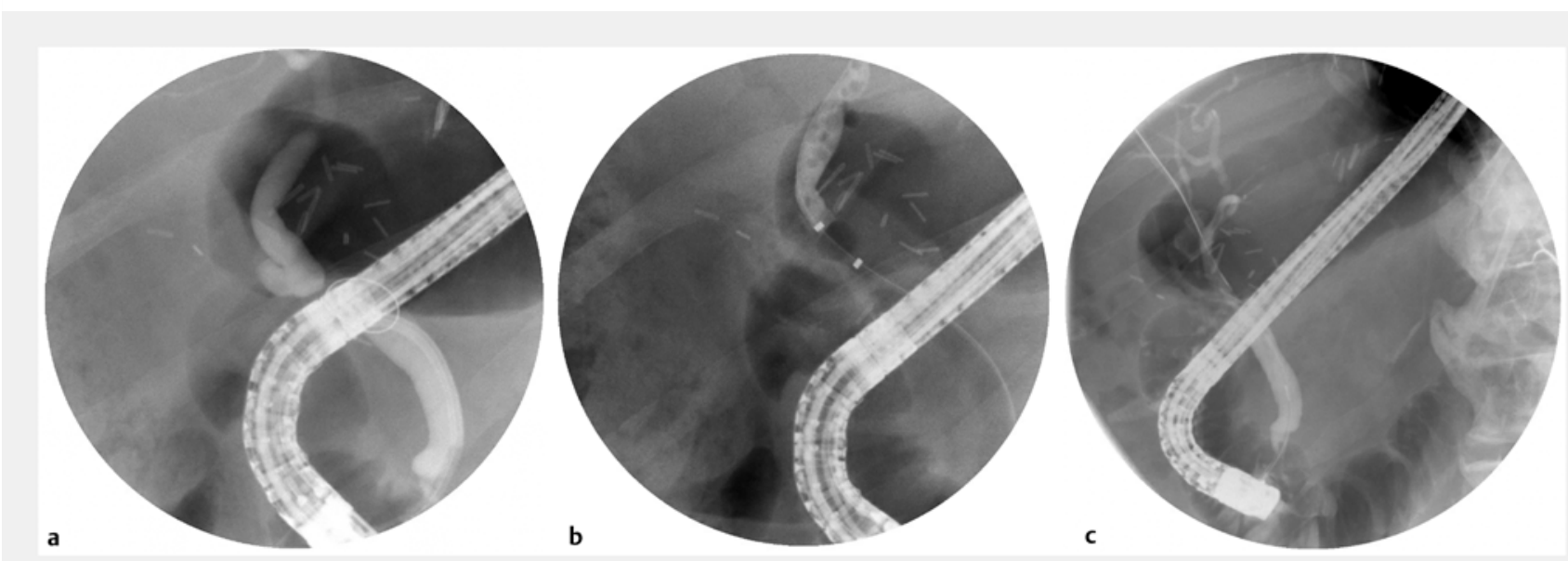

- Fig. 2 Cholangiogram images showing: a a wire coiling at the level of the stricture prior to the needle knife procedure; $\mathbf{b}$ no evidence of contrast extravasation after needle knife electrocautery of the complete anastomotic stricture; $\mathbf{c}$ the appearance at follow-up 4 weeks after the procedure. 

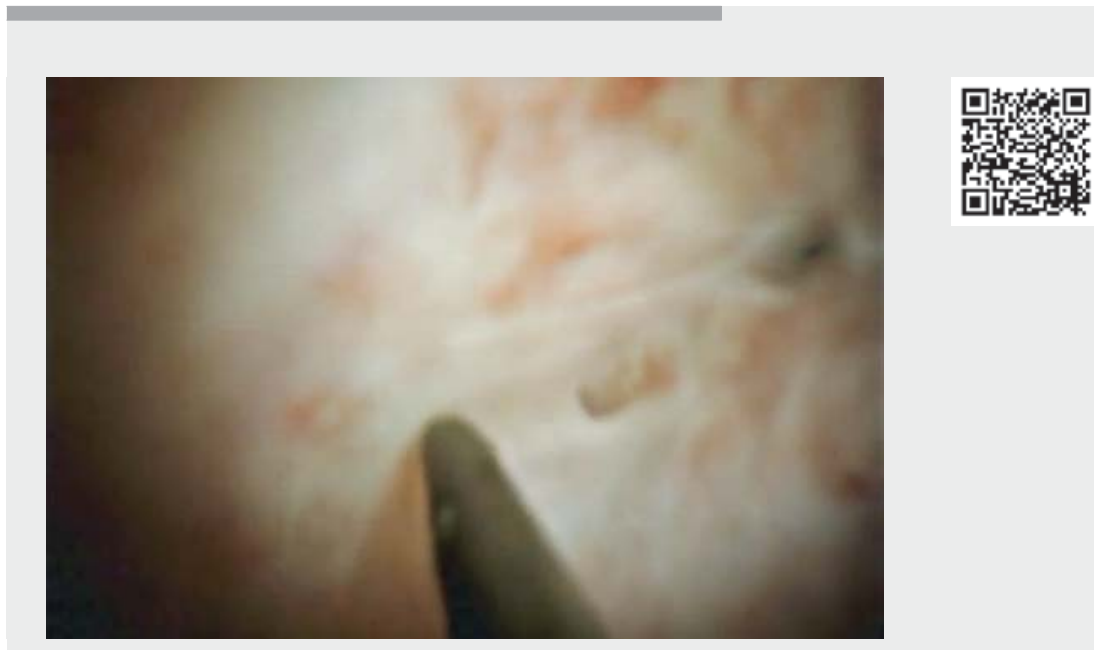

Video 1 Needle knife recanalization of a complete bile duct stricture following liver transplantation.

The authors

\section{Ramzi Mulki $\odot$, Mohamed Abdelfatah}

Department of Gastroenterology and Hepatology, The University of Alabama at Birmingham School of Medicine, Birmingham, Alabama, USA

\section{Corresponding author}

\section{Ramzi Mulki, MD}

The University of Alabama at Birmingham School of Medicine - Gastroenterology \& Hepatology, BDB 366, 1720 2nd Ave, Birmingham, Alabama 35294-3412, USA ramzi.mulki@gmail.com

\section{References}

[1] Safdar K, Atiq M, Stewart C et al. Biliary tract complications after liver transplantation. Expert Rev Gastroenterol Hepatol 2009; 3: 183-195

[2] Bukhari MA, Haito-Chavez Y, Ngamruengphong $S$ et al. Rendezvous biliary recanalization of complete biliary obstruction with direct peroral and percutaneous transhepatic cholangioscopy. Gastroenterology 2018; 154: 23-25

[3] Gupta K, Aparicio D, Freeman ML et al. Endoscopic biliary recanalization by using a needle catheter in patients with complete ligation or stricture of the bile duct: safety and feasibility of a novel technique (with videos). Gastrointest Endosc 2011; 74: 423428
[4] Martins FP, De Paulo GA, Macedo EP et al. Endoscopic biliary recanalization with a needle-knife in post liver-transplant complete anastomotic stricture. Endoscopy 2012; 44: 304-305

Bibliography

Endoscopy 2022; 54: E28-E29

DOI 10.1055/a-1353-4734

ISSN 0013-726X

published online 19.2.2021

(C) 2021. Thieme. All rights reserved.

Georg Thieme Verlag KG, Rüdigerstraße 14, 70469 Stuttgart, Germany

\section{ENDOSCOPY E-VIDEOS}

https:|/eref.thieme.de/e-videos

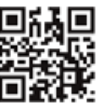

Endoscopy E-Videos is a free access online section, reporting on interesting cases and new

techniques in gastroenterological endoscopy. All papers include a high quality video and all contributions are freely accessible online.

This section has its own submission website at

https://mc.manuscriptcentral.com/e-videos 